\title{
Numerical Optimisation of The Diffuser In a Typical Turbocharger Compressor Using The Adjoint Method.
}

Kristaq Hazizi ( $\sim$ kristaq.hazizi@gmail.com )

Anglia Ruskin University Faculty of Science and Technology https://orcid.org/0000-0002-8113-8938 Ahad Ramezanpour

Anglia Ruskin University

Aaron Costall

University of Bath

\section{Research Article}

Keywords: Turbocharger compressor, k-w SST turbulence, compressor efficiency, compressor performance, optimisation, adjoint solver

Posted Date: August 26th, 2021

DOI: https://doi.org/10.21203/rs.3.rs-807892/v1

License: (a) (1) This work is licensed under a Creative Commons Attribution 4.0 International License. Read Full License 


\title{
Numerical optimisation of the diffuser in a typical turbocharger compressor using the adjoint method
}

\author{
Kristaq Hazizi ${ }^{1,},{ }^{*}$, Ahad Ramezanpour ${ }^{2}$, Aaron Costall $^{3}$ \\ 1,2, Faculty of Science \& Engineering, Anglia Ruskin University, Chelmsford CM1 1SQ, UK \\ ${ }^{3}$ Institute for Advanced Automotive Propulsion Systems (IAAPS), University of Bath, Claverton Down BA2 7AY, UK \\ Email: kristaq.hazizi@gmail.com
}

\section{Abstract}

In the automotive industry, the demand for fuel economy and emission reduction has led to the downsizing of engines and turbochargers play a leading role in compensating for the performance loss. In complex flow modelling of the compressor, effective determination of the mesh resolution is not a priori due to variation of local flow and turbulence variables. In this study, the compressible flow of a centrifugal turbocharger compressor was numerically modelled. The accuracy of the models is discussed with respect to boundary layer adaptivity for the k-w SST turbulence model.

The numerical models are investigated and verified against pick efficiency, extracted experimental points at 150,000 (rpm), along with other points of partial load at 80,000 (rpm) speed lines. The TD025-05T4 compressor of the 1.2 Litre engine Renault Megane passenger car was designed, constructed and provided experimental data (compressor map) by Mitsubishi Turbocharger and Engine Europe (MTEE). In addition, a numerical and mathematical study has been developed on the aerodynamic optimisation of the turbocharger compressor diffuser geometry.

The optimisation of the single-target problem (efficiency) of the axial flow compressor outlet stage is carried out using a new smart evolutionary optimisation technique named adjoint solver.

The Adjoint solver usually produces a surface vector field that shows how and where the geometry can be changed for optimisation based on a defined objective, efficiency in this study. Such irregular and non-parametric changes could be manufactured using recent advances in 3D printing technology.

The expected result of optimisation of the diffuser geometry started with the design point, central area, 150,000 (rpm) speed line, shows a gradual development of efficiency to an uttermost of $2.5 \%$ and the process of optimisation has been enlarged and completed on all design operating areas selected previously. The development of an optimised geometry diffuser accomplishes a wider operating range, high efficiency and robust performance due to changes in engine operating conditions in the high-pressure area.

Therefore, the optimal diffuser geometry leads to an impact on the engine's efficiency and overall performance of a passenger car for real-world drive cycles, increasing power output and improving thermal efficiency.

Keywords: Turbocharger compressor, k- $\omega$ SST turbulence, compressor efficiency, compressor performance, optimisation, adjoint solver.

\section{Nomenclature:}

$\begin{array}{ll}\pi & \text { Compression ratio } \\ \mathrm{P}_{\text {out }, \mathrm{t}} & \text { Total outlet pressure } \\ \mathrm{P}_{\mathrm{in}, \mathrm{t}} & \text { Total inlet pressure } \\ \mathrm{T}_{\text {out }, \mathrm{t}} & \text { Total outlet temperature } \\ \mathrm{T}_{\mathrm{in}, \mathrm{t}} & \text { Total inlet temperature } \\ \eta_{\mathrm{tt}} & \text { Total to total compressor efficiency } \\ \gamma & \text { Specific heat capacity ratio } \\ \rho & \text { Density } \\ \mathrm{P} & \text { Static Pressure }\end{array}$




\begin{tabular}{ll}
$u$ & Velocity \\
$\tau$ & Viscous stress \\
$\mathrm{k}$ & Turbulence kinetic energy \\
$\omega$ & Turbulence dissipation rate \\
$\mathrm{m}$ & mass \\
$\mu$ & Viscosity \\
$\mathrm{T}$ & temperature \\
$\mathrm{E}$ & Energy \\
$\mu_{\mathrm{t}}$ & Turbulence viscosity \\
$\dot{\boldsymbol{v}}$ & Volume flow rate \\
$\boldsymbol{\kappa}$ & Thermal conductivity \\
$\mathrm{C}_{\mathrm{p}}$ & Specific heat capacity at constant pressure \\
$\mathrm{J}$ & Quantity of interest, Adjoint observable \\
$\underline{\mathrm{q}}$ & Flow solution \\
$\underline{\mathrm{c}}$ & design variables \\
$\mathrm{R}_{\mathrm{i}}$ & Residuals of Navier-Stokes equations \\
$\mathrm{L}$ & Lagrangian equations \\
$\widetilde{\boldsymbol{q}}$ & Lagrange multipliers \\
$\mathrm{i}, \mathrm{j}, \mathrm{m}=$ & Indices for the Cartesian coordinates \\
$1,2,3$ & \\
$\mathrm{u}_{\mathrm{i}, \mathrm{u}}, \mathrm{u}_{\mathrm{m}}$ & Velocity components \\
$\delta \mathrm{ij}$ & Kronecker delta \\
$\sigma_{\mathrm{ij}}$ & Viscous stress tensor \\
$\left(\tau_{\mathrm{ij}}\right)$ eff & \\
$\mathrm{N}$ & \\
& Linear problems \\
\hline &
\end{tabular}

\section{Introduction}

In recent years, turbochargers have been widely used in both diesel and petrol engines to compensate for the downsizing of engines due to fuel economy and regulatory emission reductions. Accurate and effective numerical modelling of the turbochargers leads to better and faster optimisation of the design as well as the integration of the various models for specific engine housings. Recent advances in additive manufacturing open-up opportunities for non-parametric optimisation methods of the various design elements.

Recent numerical studies on turbocharger compressors while reaching a reasonable accuracy of the global performance in steady-state focus on various flow, thermal and aeroacoustics optimisation aspects of the compressors. Zhao et al. (2017) studied the effect of inlet distortion on turbocharger compressor performance. The results indicate that any inlet angle decreases the stable operation range of the compressor and shifts the choke point towards smaller flow rates. An aeroacoustics study model of the compressor has been investigated for three operating points by Broatch et al. ( 2016).

The findings of a genetic algorithm-based impeller optimisation study using one-passage CFD analysis show a 2.7-point increase in performance at the nominal point and an increased surge margin of the optimised impeller. Experimental research on turbocharger compressors is focused on understanding and delaying stall and surge phenomena that take place because of flow instability and limit the performance of the turbochargers (Marelli et al., 2014; Xinqian and Anxiong, 2015; Zheng et al., 2017; Gancedo, Guillou and Gutmark, 2018).

Considering the unsteady nature of the flow instabilities and requirement for fine mesh and high computational resources, there is limited unsteady numerical research to set the number of operating points so far that are either 1D (De Bellis and Bontempo, 2018) or limited threedimensional geometry (Mingyang et al., 2016; Semlitsch and Mihăescu, 2016; Righi et al., 2018). 
Chitale et al. (2014) investigated the boundary layer and adaptive mesh refinement with respect to flow physics consideration with respect to the standard error indicators. The focus of the study is on anisotropic element size within the turbulent boundary layer region, according to the local flow and turbulence parameters, as a means of efficient fluid dynamics numerical modelling. The results showed an excellent improvement over the flat plate and NACA 0012 aerofoil analysis.

Tuechler, Chen and Copeland (2018) applied a parametric optimisation approach coupling the ANSYS CFX with a genetic algorithm in MATLAB. The goal was to maximise isentropic efficiency at a target operating point close to the surge while avoiding major performance degradation near the choke margin. Because of 13 geometrical parameters, the results indicated that the goal optimisation efficiency gain of 2 percent was improved by around 1.9 percent, with the output decrease near the choke line being insignificant. Experimental tests on the optimised compressor show a 1-2\% improvement in the efficiency of the basic model, although peak efficiency is improved by $3.0 \%$, while the choke line remains almost unchanged.

Tosto, Alfredsson and Casalino (2018) analysed the flow field inside a turbocharger centrifugal compressor. It has been applied to Ansys CFX for steady and transient simulations using the k-omega SST turbulence model. Backflow can be observed th the operating points in the surge region.

The parametric optimisation of the centrifugal turbocharger with a vaneless diffuser was investigated by Mojaddam and Pullen (2019). The criteria include the meridional geometry, distribution of rotor blade angle and starting position of the main blades and splitters. The research gradually optimised both performance and pressure, which resulted in a $3 \%$ and $11 \%$ increase in the original configuration impeller.

The Adjoint solver used in this study is a non-parametric smart design optimisation tool that is based on obtaining detailed sensitivity data for the performance of a fluid system with respect to localised geometrical changes by computing the derivatives of the optimisation objective quantity.

According to Othmer (2014), the use of the adjoint method in the automotive industry has been limited due to the reliance of the car industry exclusively on commercial CFD software and the high complexity of the parts being optimised in the automotive industry.

The resulting computational grids will also lead to stability issues with joint simulations that have proved to be more responsive than general flow simulations to mesh defects. These problems can be partly resolved by limiting the adjoint equations (Mura, 2017).

With time, it has become increasingly common to use direct methods of design optimisation for turbomachinery in general applications, in particular for compressor blades and diffuser geometry. This has become possible with significant progress in optimisation algorithms, in particular the invention of adjoint gradient computing that provides objective sensitivity details at a lower computation cost. This allows first order optimisation approaches to complex design problems to be applied (Geuens, 2020).

This study aims to optimise the diffuser geometry, applying the adjoint solver to a typical turbocharger engine passenger car, covering six operating points on two different speed lines, including partial and full engine loads. The compressor efficiency and performance were set as the main objectives of the optimisation and the impact on overall engine performance is discussed. 


\section{Governing Equations}

The Navier-Stokes conservation of mass, momentum, and energy in conjunction with the ideal gas law has been applied to the steady-state compressible flow in this study. The governing equations are:

$$
\begin{aligned}
& \frac{\partial}{\partial x_{i}}\left(\rho u_{i}\right)=0 \\
& \text { Equation 1: Conservation of Mass } \\
& \frac{\partial}{\partial x_{j}}\left(\rho u_{i} u_{j}+p \delta_{i j}-\tau_{j i}\right)=0 \quad i=1,2,3 \\
& \text { Equation 2: Conservation of Momentum } \\
& \frac{\partial}{\partial x_{j}}\left(\rho u_{j} E+u_{j} p+\kappa \frac{\partial T}{\partial x_{j}}-u_{i} \tau_{i j}\right)=0
\end{aligned}
$$

Where,

$$
\tau_{i j}=\mu\left(\frac{\partial u_{i}}{\partial x_{j}}+\frac{\partial u_{j}}{\partial x_{i}}\right)-\frac{\mu}{3} \frac{\partial u_{k}}{\partial x_{k}} \delta_{i j}
$$

Equation 4: Viscous Stress term

The above set of equations are solved in conjunction with the ideal gas equation and the relationship between energy and temperature of the gas.

The k-w Shear-Stress Transport (SST) eddy viscosity model as proposed by Menter (1994) for turbulence kinetic energy and its dissipation rate is

$$
\begin{gathered}
\frac{\partial \rho u_{j} k}{\partial x_{j}}-\tau_{i j} \frac{\partial u_{i}}{x_{j}}+\beta^{*} \rho \omega k-\frac{\partial}{\partial x_{j}}\left\{\left(\mu+\sigma_{k} \mu_{t}\right) \frac{\partial k}{\partial x_{j}}\right\}=0 \\
\text { Equation 5: Equation of Turbulence Kinetic Energy } \\
\frac{\partial \rho u_{j} \omega}{\partial x_{j}}-\frac{r}{v_{t}} \boldsymbol{\tau}_{i j} \frac{\partial u_{i}}{x_{j}}+\boldsymbol{\beta} \rho \omega^{2}-\frac{\partial}{\partial x_{j}}\left\{\left(\boldsymbol{\mu}+\boldsymbol{\sigma}_{\omega} \boldsymbol{\mu}_{\boldsymbol{t}}\right) \frac{\partial \omega}{\partial x_{j}}\right\}-\frac{2 \rho \sigma_{\omega}}{\omega} \frac{\partial k}{\partial x_{j}} \frac{\partial \omega}{\partial x_{j}}=\mathbf{0}
\end{gathered}
$$

Equation 6: Equation of Turbulence Dissipation rate

\section{Overview of the Adjoint Method}

The adjoint solver provides a gradient-based optimisation that can automatically create a series of iterations of a design so that the mesh gradually deforms into an optimal shape to achieve single goals or multiple goals under multiple operating conditions. Its purpose is to calculate the derivative of engineering quantity via a single calculation in relation to all the inputs to the system. The engineering quantity of interest or single objective adjoint observable in this paper is the compressor efficiency. 


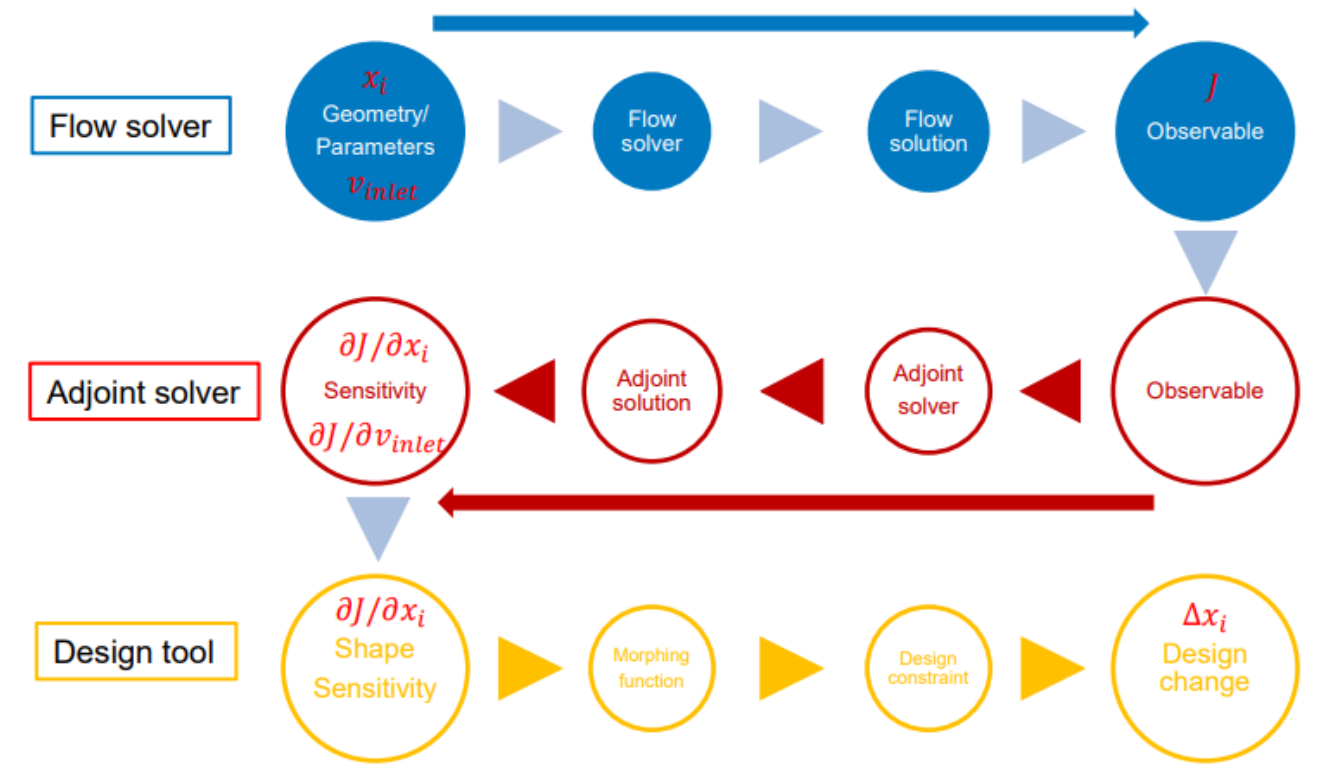

Figure 1 Adjoint solver design workflow, one full cycle (Canonsburg, 2012)

Figure 1 shows the Adjoint base design workflow for one design change cycle. Each cycle includes three sections: flow, adjoint solvers and design change, respectively. The equations for the adjoint solver are driven as follows.

Let define the quantity of interest (Adjoint observable is efficiency in this study), J, flow solution, $\underline{q}$ and inputs to the problem (flow/design variables), $\underline{c}$ (ANSYS, 2019).

$J(\underline{q}(\underline{c}), \underline{c})$ Equation 7

$R_{i}(\underline{q}(\underline{c}), \underline{c})=0$ Equation 8

Next, consider the total derivatives of both the objective function $J$ and the governing equations, $R_{i}$. These are written as follows:

We define the Lagrangian $L$ with the vector of Lagrange multipliers $\underline{\tilde{q}}$

$L(\underline{q}(\underline{c}), \underline{c}, \underline{\tilde{q}})=J+\underline{\tilde{q}}^{T} R$ Equation 9

Lagrange multipliers $\widetilde{\boldsymbol{q}}=[\mathrm{u}, \mathrm{v}, \mathrm{w}, \mathrm{p}, \mathrm{T}]$ is the adjoint variable.

Since $R=0$ everywhere, $\underline{\widetilde{q}}$ can be arbitrarily chosen:

$L(\underline{q}(\underline{c}), \underline{c}, \underline{\tilde{q}})=J$ Equation 10 and, therefore, the derivatives of the observable $J$ (Efficiency) related to design variables can be written as follows,

$\frac{d J}{d \underline{c}}=\frac{d L}{d \underline{c}}=\frac{\partial J}{\partial \underline{\underline{a}}} \frac{d \underline{q}}{d \underline{c}}+\frac{\partial J}{\partial \underline{c}}+\underline{\tilde{q}}^{T}\left[\frac{\partial R}{\partial \underline{\underline{q}}} \frac{d \underline{q}}{d \underline{c}}+\frac{\partial R}{\partial \underline{c}}\right]+\frac{d \tilde{q}^{T}}{d \underline{c}} R$ Equation 11 
If $\frac{d \tilde{q}^{T}}{d \underline{c}} R=0$ is zero, then the above equation changes to

$\frac{d J}{d \underline{c}}=\frac{d \underline{q}}{d \underline{c}}\left(\frac{\partial J}{\partial \underline{q}}+\underline{\tilde{q}}^{T} \frac{\partial R}{\partial \underline{q}}\right)+\frac{\partial J}{\partial \underline{c}}+\underline{\tilde{q}}^{T} \frac{\partial R}{\partial \underline{c}}$

Equation 12

If we choose $\underline{\tilde{q}}$ such that:

$\frac{\partial J}{\partial \underline{q}}+\underline{q}^{T} \frac{\partial R}{\partial \underline{q}}=0 \quad$ (Adjoint Equation)

Equation 13

Then,

$\frac{d J}{d \underline{c}}=\frac{\partial J}{\partial \underline{c}}+\underline{\tilde{q}}^{T} \frac{\partial R}{\partial \underline{c}} \quad$ Sensitivity of observation (Efficiency) to design variables

Equation 14

Where, $\underline{\tilde{q}}$ is the solution of the adjoint equation, it can be written in a transpose equation as follows (Mavriplis and Castagne, no date)

$\left[\frac{\partial R}{\partial \underline{q}}\right]^{T} \underline{\tilde{q}}=-\left[\frac{\partial J}{\partial \underline{q}}\right]^{T} \quad$ (Adjoint Equation, transpose equation)

Equation 15

\section{Numerical Settings}

The three-dimensional turbocharger compressor at atmospheric operating pressure and ambient temperature is $20^{\circ} \mathrm{C}$ consistent with experimental conditions. The compressor housing, impeller, and extracted computational domain are shown in Figure 2 . The computational domain has been divided into four zones; inlet, diffuser and outlet zones that are fixed and a rotational zone in between covering the impeller.
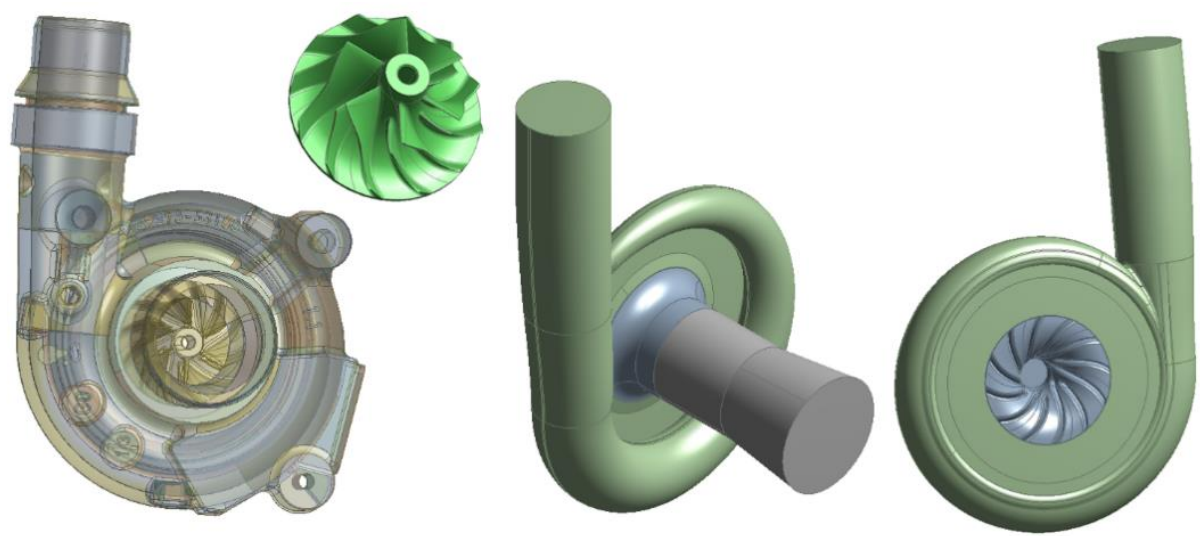

Figure 2: Design geometry and computational domain

For the mesh independency test of the diffuser optimisation purpose, six mesh sizes in total are initially considered in this research, with constant first layer mesh thickness for the first four mesh cases. Instead, for the last two mesh cases of 3.6 and 3.8 mesh elements number, the first layer thickness is 0.00005 and 0.00001 , respectively, as seen in the sample domain and boundary layer mesh in Figure 3. The approximate total mesh number cases of 1.6, 2, 2.5, 3, 3.6 and 3.8 million domain cells are seen in Table 1 . The growth rate of boundary layer mesh is set atr the recommended rate of 1.2 and 10 mesh layers are considered on volute, diffuser, inlet and impeller walls. 

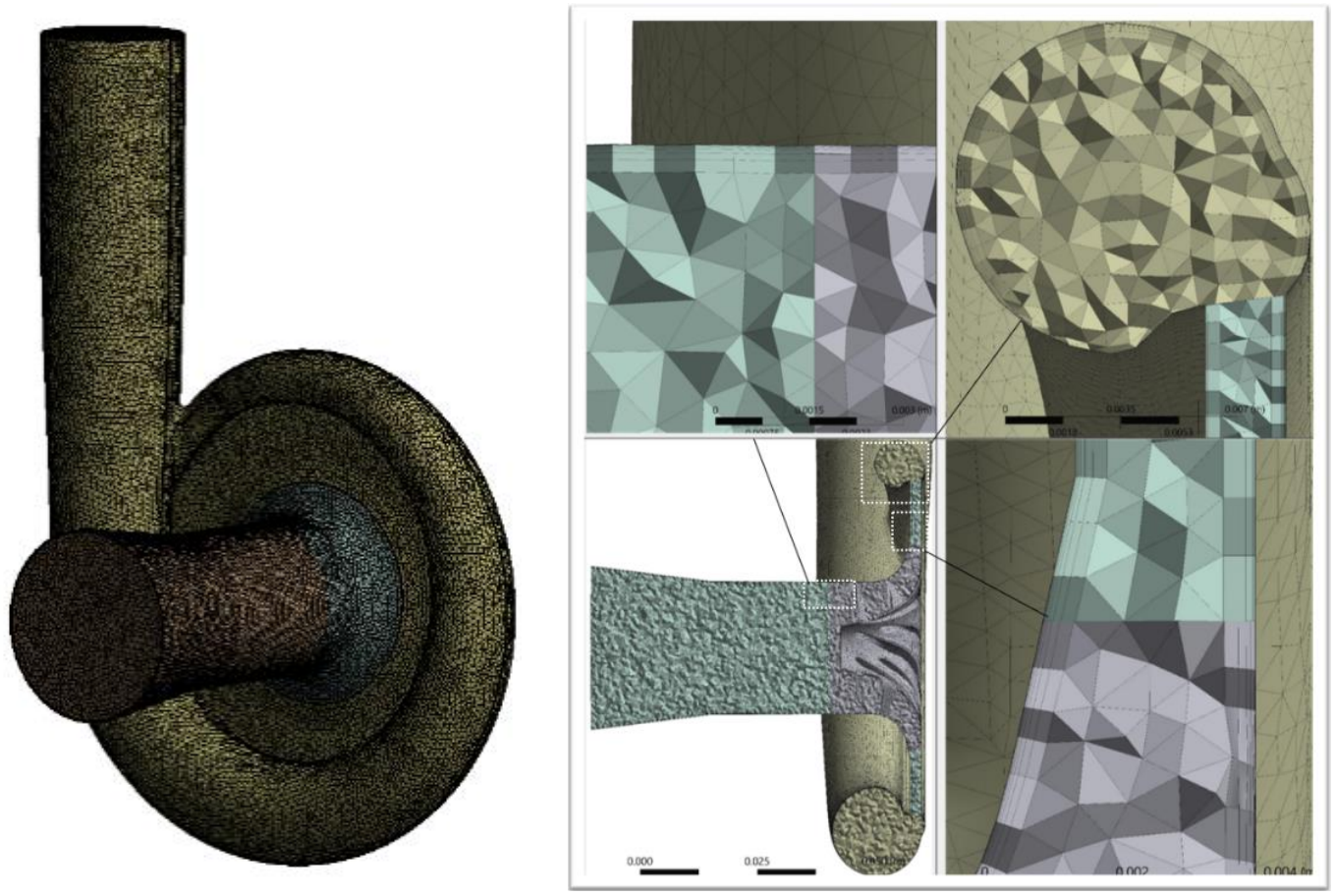

Figure 3 Sample domain and boundary layer mesh, case $3 M$

Table 1: Mesh study sizing for various cases, Speed line 150,000, Central zone

\begin{tabular}{|c|c|c|c|c|c|c|c|c|c|c|}
\hline \multicolumn{11}{|c|}{ CENTRAL ZONE SPEED 150,000 (RPM) } \\
\hline \multirow[b]{2}{*}{$\begin{array}{l}\text { Case } \\
\text { Size }\end{array}$} & \multirow{2}{*}{$\begin{array}{l}\text { First } \\
\text { mesh } \\
\text { height } Y \\
(\mathrm{~mm})\end{array}$} & \multirow[b]{2}{*}{$\begin{array}{l}\text { Total } \\
\text { mesh } \\
\text { number }\end{array}$} & \multirow[b]{2}{*}{ Efficiency } & \multirow[b]{2}{*}{$\begin{array}{c}\text { Torque } \\
(\mathrm{Nm})\end{array}$} & \multicolumn{6}{|c|}{ Y Plus (mm) } \\
\hline & & & & & diffuser & Inlet & $\begin{array}{l}\text { Inlet } \\
\text { Wall }\end{array}$ & Outlet & Volute & Impeller \\
\hline 1.6 & 0.001 & 1.699 & 0.756 & 0.184 & $0.1-0.6$ & $0-0.25$ & $0.1-1.4$ & $0-0.35$ & $0-8$ & $0-7.5$ \\
\hline 2 & 0.001 & 2.077 & 0.757 & 0.184 & $0.1-0.7$ & $0-0.25$ & $0.1-1.6$ & $0-0.55$ & $0 .-9$ & $0-5.5$ \\
\hline 2.5 & 0.001 & 2.536 & 0.756 & 0.184 & $0.1-1$ & $0-0.25$ & $0-0.55$ & $0-0.25$ & $0-7$ & $0-4.5$ \\
\hline 3 & 0.001 & 3.007 & 0.759 & 0.183 & $0.15-0.75$ & $0-0.25$ & $0.1-0.6$ & $0-0.20$ & 0.4 & $0-4.5$ \\
\hline 3.6 & 0.00005 & 3.681 & 0.757 & 0.184 & $0.01-0.035$ & $0-0.014$ & $0.05-0.01$ & $0-0.01$ & $0-3.5$ & $0-1.4$ \\
\hline 3.8 & 0.00001 & 3.785 & 0.761 & 0.184 & $0.001-0.006$ & $0-0.0025$ & $0.02-0.045$ & $0-0.002$ & $0-3.5$ & $0-1.4$ \\
\hline
\end{tabular}

An implicit pressure-velocity coupled solver is used with second ordered discretisation for all flow, energy, and turbulence parameters. The green-Gauss node based is used for spatial discretisation where a weighted average of the cell values is constructed in each node to derivatives, which is more accurate for unstructured tetrahedral cells. For accelerated convergence, a pseudo-transient approach was used, in which forms of implicit under-relaxation are controlled by pseudo time step size. The viscosity $\mu$ in equation 4 varies with temperature according to Sutherland law. The $\mathrm{K}=0.0242 \mathrm{w} / \mathrm{m} . \mathrm{K}$ is considered constant thermal conductivity and the specific heat capacity is considered $\mathrm{C} p=1006.43 \mathrm{~J} / \mathrm{kg} . \mathrm{K}$.

As the turbocharger compressor stage takes air from the atmosphere, atmospheric conditions are used. The inlet boundary of the compressor was set to the mass flow rate and the outlet boundary was set as the pressure outlet at six different operating points considered in this research.

Based on the residual monitor plot shown in Figure 4, all the equations are converged within the convergence tolerance. Also, it can be observed that the numerical efficiency and moment values are a small change which is negligible and not considered as seen and summarised in Table 1. Then, it can be concluded after this mesh study that the values of numerical efficiency and moments are 
stable and do not depend on mesh refinement. In Table 1, summarises the y plus values wherein most compressor areas have achieved a value of $<1$ as expected and in the areas of volute and impeller is reached a value $<5$. The y plus values show that the numerical model solution is accurate and as expected. For further optimisation purposes of the diffuser geometry, it was selected case 3 $M$, to follow the baseline and optimised geometry simulations.
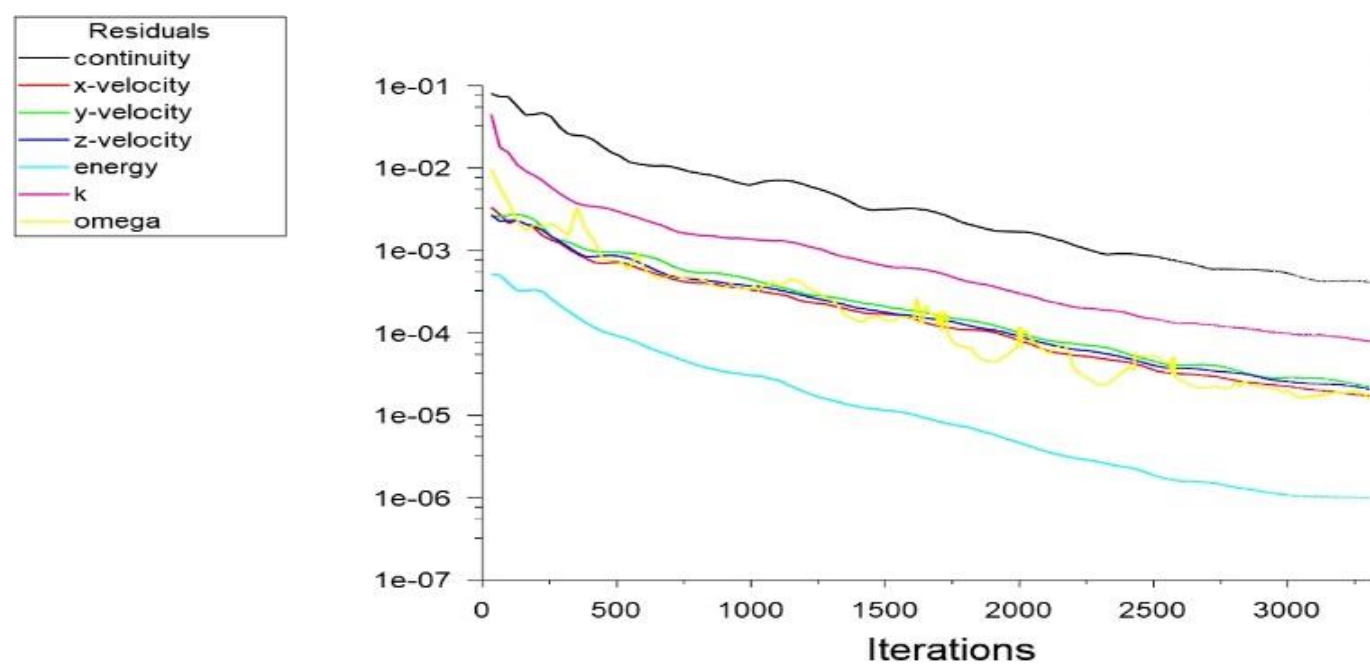

Figure 4 A typical residual plot for the case of $3 \mathrm{M}$ million mesh used in this study

The total pressure ratio and efficiency are verified as global variables with respect to the experimental data shown in Table 2. For this study, three operating points on a pick efficiency curve along a 150,000 rpm speed line and three points on partial load along an 80,000 rpm speed line are considered. The range of points selected to cover diverse operating loads and variations in relation to the surge and choke lines of the compressor map.

Table 2. Experimental data from Mitsubishi Turbocharger and Engine Europe (MTEE)

\begin{tabular}{|l|l|l|l|l|}
\hline $\begin{array}{l}\text { Operating } \\
\text { points }\end{array}$ & $\begin{array}{l}\text { Impeller } \\
\text { angular } \\
\text { velocity } \\
\text { (rpm) }\end{array}$ & $\begin{array}{l}\text { Volume } \\
\text { flow rate } \\
\text { (m3/s) }\end{array}$ & $\begin{array}{l}\text { Output over } \\
\text { input total } \\
\text { pressure ratio, }\end{array}$ & $\begin{array}{l}\text { Compressor } \\
\text { Normalized } \\
\text { efficiency }\end{array}$ \\
\hline 1 Surge & 150000 & 0.01840 & 1.70542 & 0.93 \\
\hline $\mathbf{2}$ Central & 150000 & 0.04204 & 1.65297 & 1 \\
\hline 3 Choke & 150000 & 0.06816 & 1.25516 & 0.61 \\
\hline 4 Surge & 80000 & 0.00813 & 1.18696 & 0.844 \\
\hline $\mathbf{5}$ Central & 80000 & 0.02130 & 1.15564 & 0.935 \\
\hline $\mathbf{6}$ Choke & 80000 & 0.03490 & 1.07014 & 0.610 \\
\hline
\end{tabular}

The pressure ration, $\pi$, is calculated as the ratio of total outlet to inlet pressures. The total-to-total efficiency, $\eta_{\mathrm{tt}}$, is calculated as the isentropic ideal work input over the actual work input. The formulations for these parameters are

$$
\begin{array}{rr}
\pi=\frac{P_{\text {out }, t}}{P_{\text {in, }, t}} & \text { Equation 16: Total pressure ratio } \\
\eta_{t t}=\frac{\pi^{(\gamma-1) / \gamma_{-1}}}{\left(T_{\text {out }, t} / T_{\text {in }, t}\right)-1} & \text { Equation 17: Total to total compressor efficiency }
\end{array}
$$

The predicted numerical efficiency result values achieved for the Baseline diffuser geometry are summarised in Table 3. 
Table 3 Baseline Numerical Efficiency Results for all Operating Points

\begin{tabular}{|c|c|c|c|c|c|c|}
\hline \multirow{3}{*}{ Case 3M } & \multicolumn{6}{|c|}{ Operating Points } \\
\hline & \multicolumn{3}{|c|}{80,000 rpm } & \multicolumn{3}{|c|}{$150,000 \mathrm{rpm}$} \\
\hline & (Surge) & (Central) & (Choke) & (Surge) & (Central) & (Choke) \\
\hline $\begin{array}{l}\text { Baseline } \\
\text { Efficiency }\end{array}$ & 0.734 & 0.767 & 0.506 & 0.729 & 0.759 & 0.503 \\
\hline
\end{tabular}

In a recent research paper, (Hazizi et al., 2019), they investigated and analysed the fluid domain of the same compressor about the pressure ratio and efficiency. The numerical result of a stable point selected close to the central area, speed line 150,000, has been compared with experimental data extracted from MTEE, validating the numerical model. Numerical analysis of pressure ratio and efficiency has been extended and compared with experimental data for all other design points of the compressor map selected.

Further numerical simulations, optimisation purposes covering all design areas cases ( 6 cases) were performed in this study, comparing both configurations, baseline and optimised compressor diffuser geometry.

\section{Results and Discussions}

The baseline and optimised diffuser geometry efficiency values and the improved percentage are shown in Table 4 for all the case studies. The predicted efficiency results of optimised diffuser geometry compared with baseline diffuser geometry show an increase in efficiency for all case studies. In particular, case areas speed line of 150,000 rpm, achieved an improvement of approximately $5.36 \%$ of efficiency value in the choke area. It can be observed that the efficiency improvement is significant for the speed line at 150,000 rpm and the operating point close to the choke. That can be linked to the high mass flow rate sensitivity to the change of diffuser geometry.

Table 4 Adjoint versus Baseline Results for all Operating Points

\begin{tabular}{|l|l|c|c|c|}
\hline \multirow{2}{*}{ MAP AREA } & SPEED LINE (rpm) & \multicolumn{2}{|c|}{ COMPRESSOR EFFICIENCY } & \multirow{2}{*}{ IMPROVEMENT (\%) } \\
\cline { 3 - 5 } & & BASELINE & ADJOINT & \\
\hline SURGE & CASE 1 (150,000) & 0.729 & 0.746 & 2.44 \\
\hline CENTRAL & CASE 2 (150,000) & 0.759 & 0.779 & 2.63 \\
\hline CHOKE & CASE 3 (150,000) & 0.503 & 0.530 & 5.36 \\
\hline SURGE & CASE 4 (80,000) & 0.734 & 0.744 & 1.36 \\
\hline CENTRAL & CASE 5 (80,000) & 0.767 & 0.777 & 1.3 \\
\hline CHOKE & CASE 6 (80,000) & 0.506 & 0.510 & 0.79 \\
\hline
\end{tabular}

The residual plots for baseline and adjoint design iterations of optimised diffuser geometry, for all operating areas, are shown graphically in Figure 5. The results of optimisation achieved in this paper are based on the optimal local efficiency values operating points as shown in Figure 5, for each case study. It can be observed that the efficiency increases up to a certain design iteration, which is the maximum local efficiency value and then starts decreasing at a certain design iteration. 


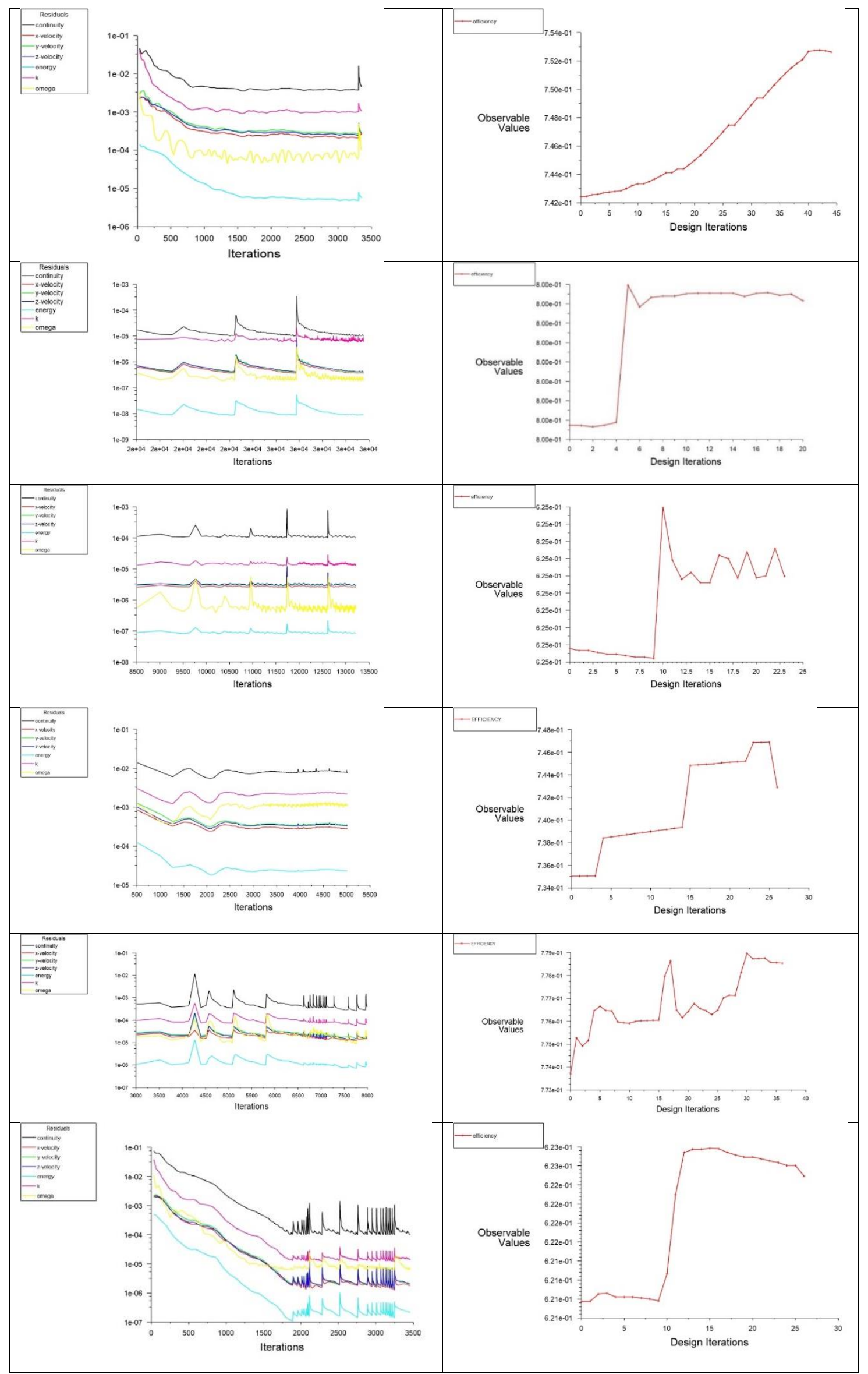

Figure 5 Residual Monitors Plot Baseline and Adjoint design iterations (Left and Right), All operating areas, Surge, Central and Choke from top to bottom, Speed lines 80,000 rpm and 150,000 rpm 


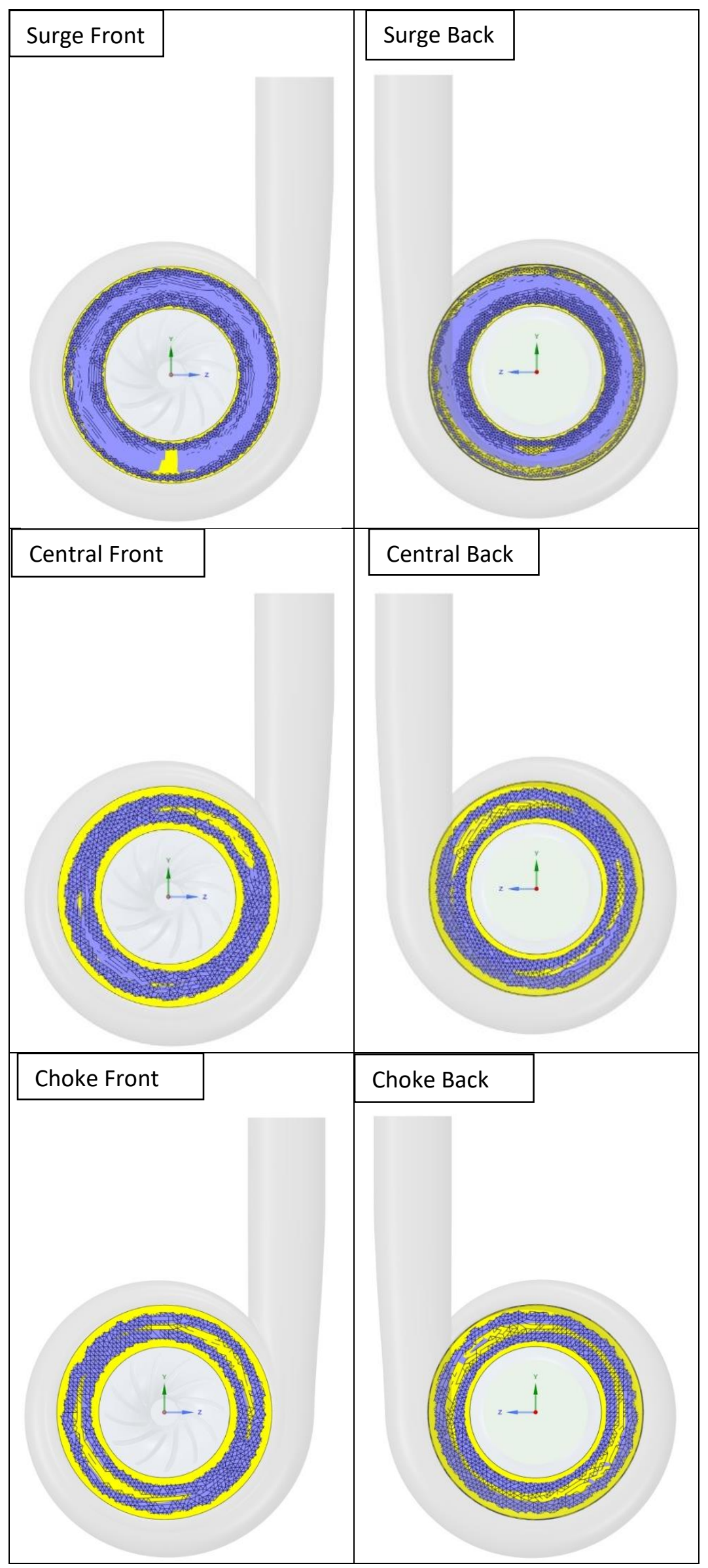

Figure 6 Diffuser Geometry Changes, Surge, Central, and Choke area (Top, Middle and Bottom), Speedline 80,000rpm 


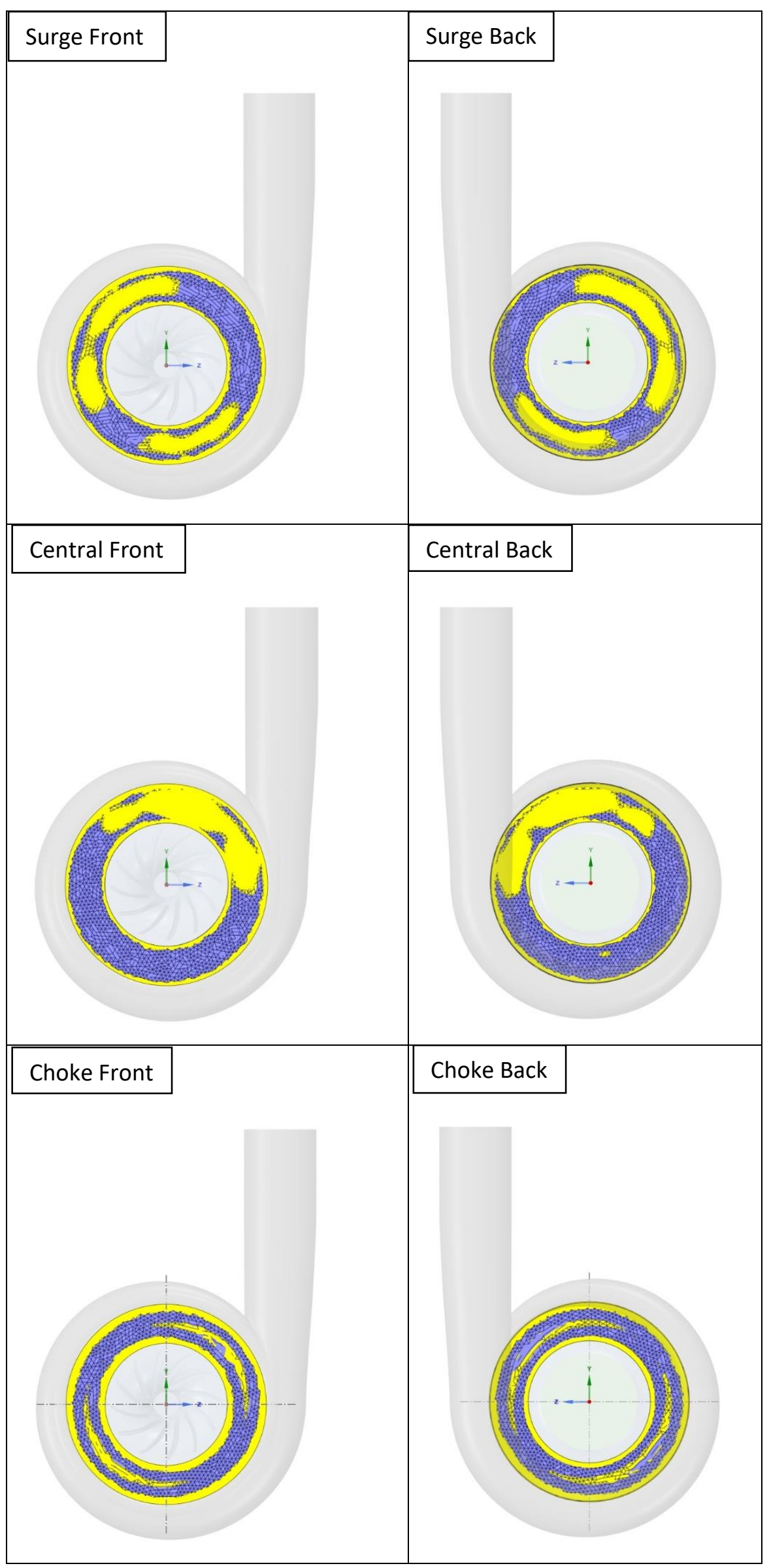

Figure 7 Diffuser Geometry Changes, Surge, Central, and Choke area (Top, Middle and Bottom), Speedline 150,000rpm 
Figure 6 shows the geometry change of optimised diffuser geometry versus baseline geometry for operating areas surge, central and choke, speed line 80,000 (rpm). Instead, Figure 7 shows the geometry change of optimised diffuser geometry versus baseline geometry for operating areas surge, central and choke, speed line of 150,000 (rpm).

To differentiate the geometry change, the baseline diffuser geometry is made yellow and optimised diffuser geometry is made purple. There can be observed areas where the optimised geometry has shrunk. Instead, Table 5, shows the difference in geometry volume between optimised diffuser geometry and baseline diffuser geometry.

Table 5 Diffuser Geometry Change for Operating areas, Surge, central and choke, Speedline 80,000 (rpm) and 150,000 (rpm)

\begin{tabular}{|c|c|c|c|}
\hline \multicolumn{4}{|c|}{ CASE 3M, SURGE, CENTRAL and CHOKE AREAS, SPEED LINES 150,000 and $80,000(\mathrm{rpm})$} \\
\hline \multicolumn{3}{|c|}{ Volume $\left(\mathrm{mm}^{3}\right)$} & \multirow{2}{*}{ Difference $\left(\mathrm{mm}^{3}\right)$} \\
\hline \multicolumn{2}{|c|}{ Baseline geometry } & 6253.861 & \\
\hline \multirow{3}{*}{$\begin{array}{l}\text { Optimised geometry } \\
150,000(\mathrm{rpm})\end{array}$} & SURGE & 5925.7379 & -328.1231 \\
\hline & CENTRAL & 6080.4786 & -173.3824 \\
\hline & CHOKE & 5585.0872 & -668.7738 \\
\hline \multirow{3}{*}{$\begin{array}{c}\text { Optimised geometry } \\
80,000(\mathrm{rpm})\end{array}$} & SURGE & 6048.0847 & -205.7763 \\
\hline & CENTRAL & 5592.6483 & -661.2127 \\
\hline & CHOKE & 5708.7985 & -545.0625 \\
\hline
\end{tabular}

Figure 8 and Figure 10, show the contours of absolute pressure, speed lines; 80,000 (rpm) and 150,000 (rpm), respectively, for both configuration; optimised diffuser geometry and baseline diffuser geometry.

It can be observed that the total pressure for both configurations, speed lines; $80,000 \mathrm{rpm}$ and $150,000 \mathrm{rpm}$, increased radially at the exit of the diffuser geometry. Due to the increased area between the diffuser entrance and the exit, kinetic energy is converted into pressure.

The absolute pressure results summarised in Table 6 appear to make sense and to be compatible with our expectations as the absolute pressure values are increased in the optimised diffuser geometry versus baseline diffuser geometry in all operating areas.

Table 6 Absolute pressure contour value for all cases

\begin{tabular}{|l|l|c|c|}
\hline \multirow{2}{*}{ Map area } & Speed line $(\mathrm{rpm})$ & \multicolumn{2}{|c|}{ Absolute pressure (Pa) } \\
\hline Surge & Case 1 $(150,000)$ & 169844 & Adjoint \\
\hline Central & Case 2 $(150,000)$ & 165735 & 169935 \\
\hline Choke & Case 3 $(150,000)$ & 143872 & 165774 \\
\hline Surge & Case 4 $(80,000)$ & 119026 & 143942 \\
\hline Central & Case 5 $(80,000)$ & 116941 & 119092 \\
\hline Choke & Case 6 $(80,000)$ & 113577 & 116991 \\
\hline
\end{tabular}

Instead, Figure 9 and Figure 11 show the contours of total temperature, speed lines; 80,000 (rpm) and 150,000 (rpm), respectively, for both configuration, optimised diffuser geometry and baseline diffuser geometry. 
It can be observed that the total temperature for both configurations, speed line $80,000 \mathrm{rpm}$, increased radially at the exit of the diffuser geometry. Due to the increased area between the diffuser entrance and the exit, kinetic energy is converted into pressure.

However, the total temperature results summarised in Table 7 do now show a certain pattern across the speed lines and the map area between baseline and adjoint results.

Therefore, based on equation 17 , the efficiency value is linked to the variation of the absolute pressure in the numerator and the variation of the total temperature in the denominator.

It can be observed that despite some cases where the total temperature shows no change or slight increase, the absolute pressure has increased for all cases. Overall, the compressor efficiency results value achieved an improvement for all cases of both speed lines.

Table 7 Total temperature contour value for all cases

\begin{tabular}{|l|l|c|c|}
\hline \multirow{2}{*}{ Map area } & \multirow{2}{*}{ Speed line $(\mathrm{rpm})$} & \multicolumn{2}{|c|}{ Total temperature $(\mathrm{K})$} \\
\hline Surge & Case 1 $(150,000)$ & 347.218 & Adjoint \\
\hline Central & Case 2 $(150,000)$ & 354.8 & 347.218 \\
\hline Choke & Case 3 $(150,000)$ & 347.218 & 355.389 \\
\hline Surge & Case 4 $(80,000)$ & 316.522 & 347.218 \\
\hline Central & Case 5 $(80,000)$ & 309.677 & 316.079 \\
\hline Choke & Case 6 $(80,000)$ & 307.716 & 309.760 \\
\hline
\end{tabular}

Therefore, the increase of efficiency results in all case study both speed lines in the optimal diffuser geometry leads to impact the engine on efficiency and overall performance of a passenger car for real-world drive cycles, increasing power output and improving thermal efficiency. 


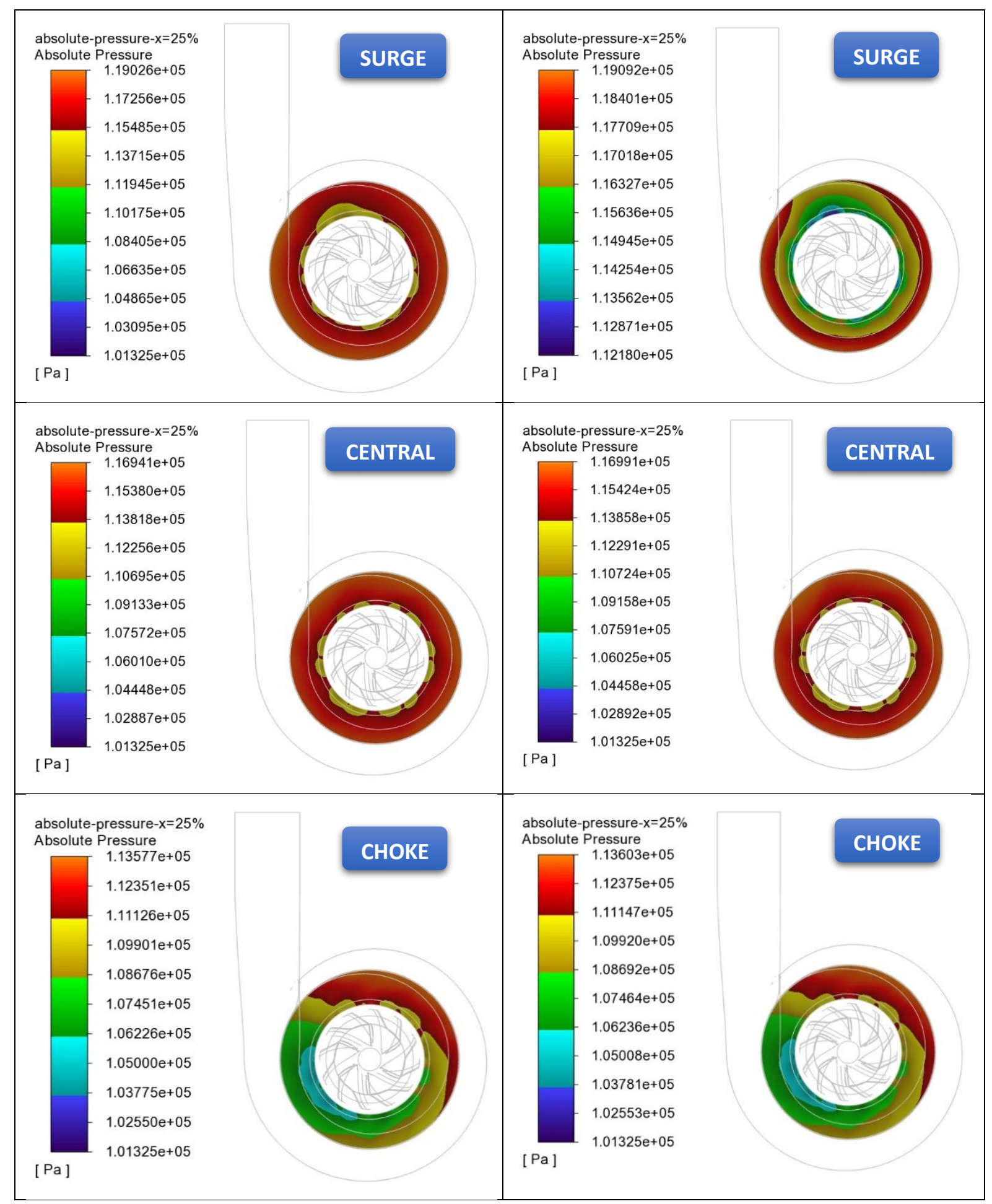

Figure 8 Contours Absolute Pressure $x=25 \%$, Speedline $80,000 \mathrm{rpm}$, Surge (Top), central (Middle) and choke (Bottom), Baseline (left) and Optimised diffuser geometry (Right) 


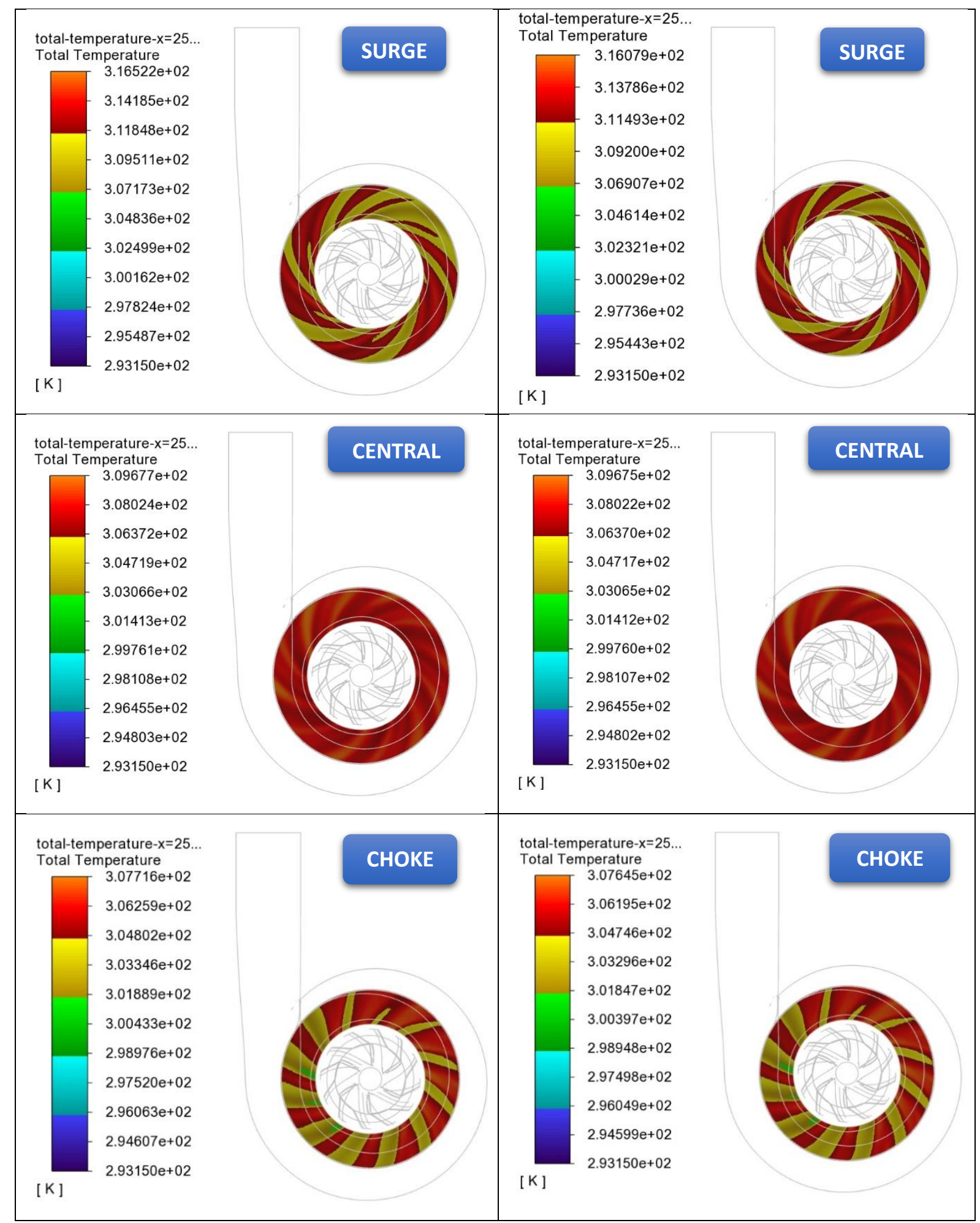

Figure 9 Contours Total Temperature $x=25 \%$, Speedline 80,000 rpm, Surge (Top), centra (Middle)l and choke (Bottom), Baseline (Left) and Optimised (Right) diffuser geometry 


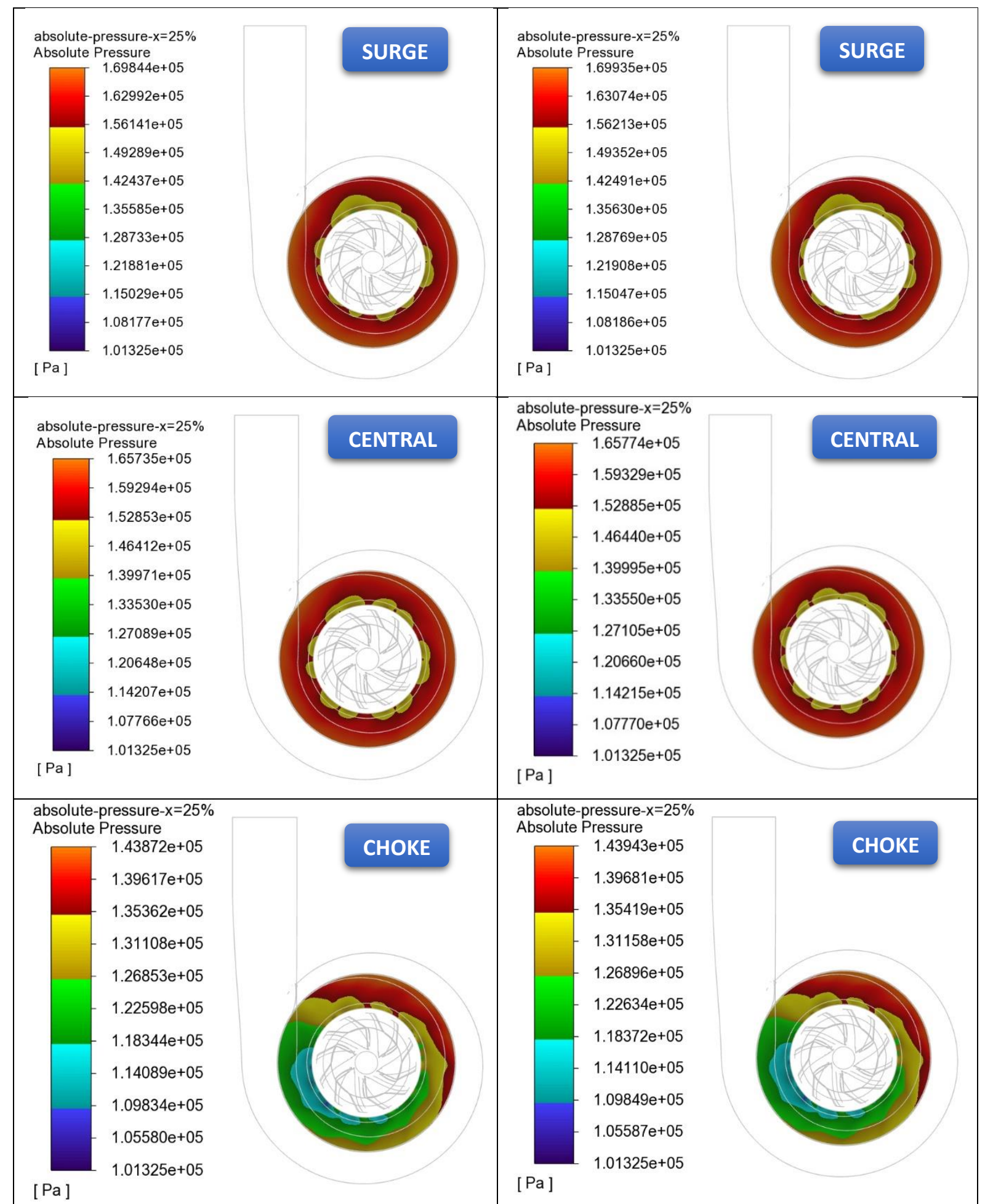

Figure 10 Contours Absolute Pressure $\mathrm{x}=25 \%$, Surge (Top), central (Middle) and choke (Bottom), Speedline 150,000 rpm, Baseline (Left) and Optimised diffuser geometry (Right) 


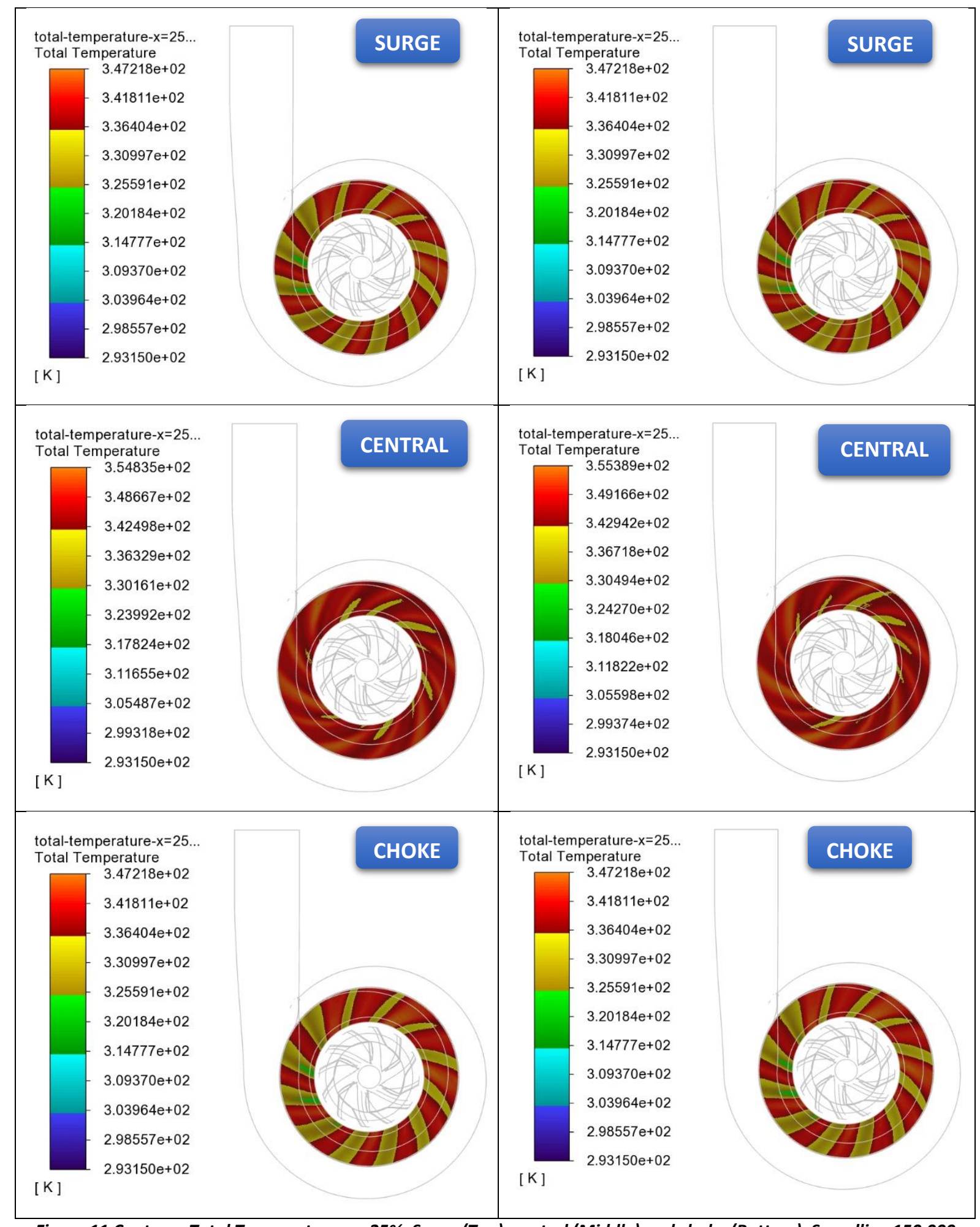

Figure 11 Contours Total Temperature $x=25 \%$, Surge (Top), central (Middle) and choke (Bottom), Speedline 150,000 rpm, Baseline (Left) and Optimised diffuser geometry (Right)

Most of the turbocharger operation takes place in the stable area: the central area of 150,000 and $80,00 \mathrm{rpm}$ (full and half load). Figures 6 and 7 show that the geometry change for optimisation of the central area is almost identical for both speed lines. A typical cross-section of the optimum geometry for case study number 2 has been shown in Figure 12 for both the front and back of the diffuser geometry. The geometry has shrunk on either side of the diffuser, with the maximum shrinking point 
at around slightly closer to the diffuser inlet. Such a change in practical terms is possible with laser sintering techniques.

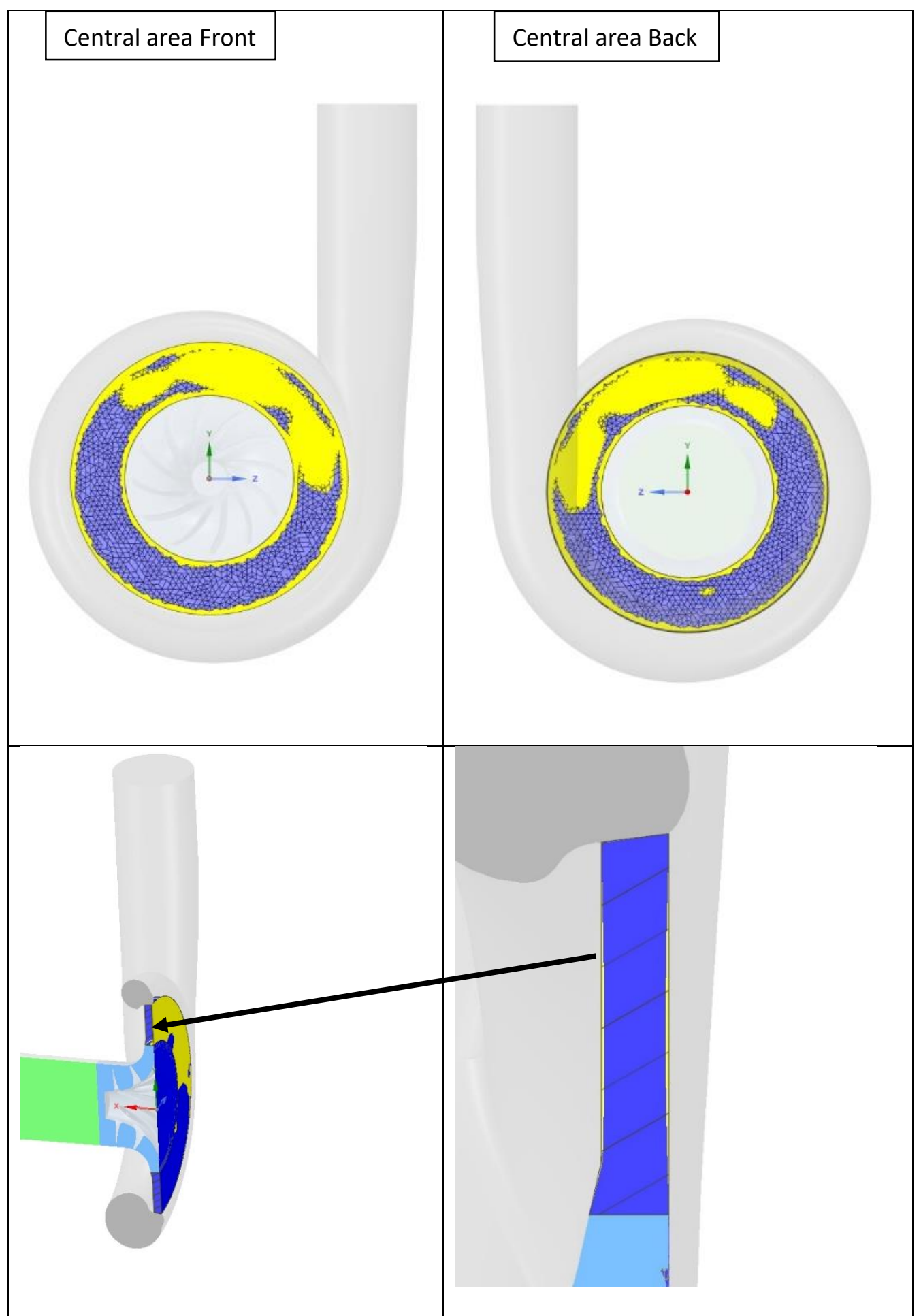

Figure 12 Diffuser Geometry Changes Operating Central area, Speedline 150,000rpm, 3D front view left side and 3D back view right side

The first order engine calculations show that improvements in the turbocharger compressor efficiency could lead to engine power output and efficiency improvements of about $0.05 \%$. 


\section{Conclusions}

A gradient-based solution approach employing a new adjoint shaping optimisation for ideal gas turbulent flow applications is presented in this study to optimise the diffuser in the car turbocharger compressor diffuser. The novelty of this research is to adapt the adjoint solver to an observable quantity, compressor efficiency in this study, and link the associated solution to the surface adjoint sensitivity, leading to mesh morphing techniques to change the diffuser geometry and improve the compressor efficiency.

The step differentiation works well with the Jacobian equation approach to solve the RANS equations. The k-omega SST turbulence model for two speed lines of 150,000 and 80,00 rpm and with three areas for each speed line studied. The three areas include choke, stable, and surge from the compressor map.

The following conclusions were obtained:

1. The efficiency values for all operating areas and speed lines increased; the maximum increase was $5.36 \%$ for the choke area of the $150,000 \mathrm{rpm}$ speed line.

2. While the geometry variation of the optimised diffuser is different for the choke and surge optimisation, the geometry change is consistent in the stable central area for both speed lines. Therefore, the optimisation of the diffuser is possible for the real world cycle (half and full load engine operation).

3. The results show that such optimisation is possible by tightening the flow on either side of the diffuser close to the compressor exit and with the maximum airflow shrinking area slightly closer to the diffuser inlet.

4. Within the central areas (stable), the efficiency value improvement in both speed lines is in the range of $1.3 \%$ to $2.63 \%$.

The improved compressor efficiency is expected to impact a typical care engine across the full and half load real-world drive cycles, increasing power output and efficiency by about $0.05 \%$.

\section{References}

ANSYS (2019) Lecture 01: Introduction ANSYS Fluent Adjoint Solver.

De Bellis, V. and Bontempo, R. (2018) 'Development and validation of a 1D model for turbocharger compressors under deep-surge operation', Energy, 142, pp. 507-517. doi: 10.1016/j.energy.2017.10.045.

Broatch, A. et al. (2016) 'Numerical and experimental analysis of automotive turbocharger compressor aeroacoustics at different operating conditions', International Journal of Heat and Fluid Flow, 61, pp. 245-255. doi: 10.1016/j.ijheatfluidflow.2016.04.003.

Canonsburg, T. D. (2012) ANSYS FLUENT Adjoint Solver, Ratio. Add the publication source

Chitale, K. C. et al. (2014) 'Boundary layer adaptivity for incompressible turbulent flows', in 11th World Congress on Computational Mechanics, WCCM 2014, 5th European Conference on Computational Mechanics, ECCM 2014 and 6th European Conference on Computational Fluid Dynamics, ECFD 2014. Barcelona: IACM, pp. 5439-5459.

Gancedo, M., Guillou, E. and Gutmark, E. (2018) 'Effect of bleed slots on turbocharger centrifugal compressor stability', International Journal of Heat and Fluid Flow, 70(70), pp. 206-215. doi: 
10.1016/j.ijheatfluidflow.2017.12.007.

Geuens, C. S. E. F. (2020) Adjoint-Based Inverse Design of Axial Com-pressor Airfoils Development \& Evaluation of a New Design Method. Available at: http://repository.tudelft.nl/.

Hazizi, K. et al. (2019) 'Numerical analysis of a turbocharger compressor', in E3S Web of Conferences. doi: 10.1051/e3sconf/201912806012.

Marelli, S. et al. (2014) 'Experimental analysis on the performance of a turbocharger compressor in the unstable operating region and close to the surge limit', Experimental Thermal and Fluid Science, 53, pp. 154-160. doi: 10.1016/j.expthermflusci.2013.11.025.

Mavriplis, D. J. and Castagne, M. (no date) Adjoint-Based Sensitivity Analysis for Computational Fluid Dynamics Motivation.

Menter, F. R. (1994) 'Two-equation eddy-viscosity turbulence models for engineering applications', AIAA Journal, 32(8), pp. 1598-1605. doi: 10.2514/3.12149.

Mingyang, Y. et al. (2016) 'Unsteady influence of Self Recirculation Casing Treatment (SRCT) on high pressure ratio centrifugal compressor', International Journal of Heat and Fluid Flow, 58, pp. 19-29. doi: 10.1016/j.ijheatfluidflow.2015.12.004.

Mojaddam, M. and Pullen, K. R. (2019) 'Optimization of a centrifugal compressor using the Design of Experiment technique', Applied Sciences (Switzerland), 9(2). doi: 10.3390/app9020291.

Mura, G. L. (2017) Mesh Sensitivity Investigation in the Discrete Adjoint Framework.

Othmer, C. (2014) 'Adjoint methods for car aerodynamics', Journal of Mathematics in Industry, 4(1), pp. 1-23. doi: 10.1186/2190-5983-4-6.

Righi, M. et al. (2018) 'Three-dimensional through-flow modelling of axial flow compressor rotating stall and surge', Aerospace Science and Technology, 78, pp. 271-279. doi: 10.1016/j.ast.2018.04.021.

Semlitsch, B. and Mihăescu, M. (2016) 'Flow phenomena leading to surge in a centrifugal compressor', Energy, 103, pp. 572-587. doi: 10.1016/j.energy.2016.03.032.

Tosto, F., Alfredsson, H. and Casalino, L. (2018) Investigation of performance and surge behavior of centrifugal compressors through CFD simulations.

Tuechler, S., Chen, Z. and Copeland, C. (2018) Multipoint Optimisation of Radial Compressor Using Computational Fluid Dynamics and Genetic Algorithm.

Xinqian, Z. and Anxiong, L. (2015) 'Experimental Investigation of Surge and Stall in a High-Speed Centrifugal Compressor', Journal of Propulsion and Power, 31(3), pp. 815-825. doi: 10.2514/1.B35448.

Zhao, B. et al. (2017) 'Impact of inlet distortion on turbocharger compressor stage performance', Applied Thermal Engineering, 124, pp. 393-402. doi: 10.1016/j.applthermaleng.2017.05.181.

Zheng, X. et al. (2017) 'Experimental investigation of surge and stall in a turbocharger centrifugal compressor with a vaned diffuser', Experimental Thermal and Fluid Science, 82, pp. 493-506. doi: 10.1016/j.expthermflusci.2016.11.036. 